\title{
USING SELF-GENERATED IDENTIFICATION CODES TO MATCH QUESTIONNAIRES IN PANEL STUDIES OF ADOLESCENT SUBSTANCE USE
}

\author{
JOEL W. GRUBE \\ Prevention Research Center \\ MARK MORGAN \\ St. Patrick's College. Dublin, Ireland \\ KATHLEEN A. KEARNEY \\ University of California, San Francisco
}

\begin{abstract}
The usefulness of self-generated codes for anonymously linking data in panel studies of adolescent substance use was investigated in a study of Irish postprimary students and sample bias resulting from this procedure considered. A seven element code exactly matched $71 \%$ of questionnaires over one month when school absences were taken into account. Allowing codes to differ on one element to compensate for respondent errors increased matching success to $88 \%$ without resulting in appreciable mismatching. Unmatched compared with exactly matched respondents tended to be male, lower SES. have more spending money, and were less closely bonded to school and religion. They also were more involved in smoking, drinking, and drug use and had more favorable beliefs toward these behaviors. Off-one respondents generally were intermediate on these measures. However, the differences were small and the characteristics of the combined matched respondents closely resembled those of the total sample. When predicting substance use, the regression coefficients were quite similar for the matched and unmatched groups and the total sample. The data thus provide evidence for the usefulness of self-generated codes in panel and longitudinal studies of adolescents when anonymity and confidentially are of concern.
\end{abstract}

Researchers conducting panel or longitudinal studies of adolescent substance use often are faced with the problem of maintaining conditions of anonymity and yet matching survey materials obtained from the same respondents at two or more points in time. One method for potentially achieving both of these goals is the use of self-generated identification codes (Josephson \& Rosen, 1978; Kandel, Kessler, \& Margulies, 1978; Kearney, Hopkins, Mauss, \& Weisheit. 1984). Self-generated identification codes consist of information provided by survey respondents about stable personal characteristics (e.g., birth date, middle initial, number of older siblings). This information is combined into an identifier that can be used to link questionnaires, but which cannot be associated with a specific respondent without a great deal of difficulty.

Although self-generated identification codes appear to offer an ingenious solution to a difficult problem, their usefulness in studies of adolescents may be limited. In

The research upon which this paper is based was funded by the Commission of the European Communities and the Economic and Social Research Institute of Dublin. Ireland. Support for the first author during the preparation of this paper was provided by National Institute on Alcohol Abuse and Alcoholism grants AA07240 to the Alcohol Research Group. Berkeley, CA and AA06282 to the Prevention Research Center. Berkeley, CA.

Requests for reprints should be sent to Joel Grube, Prevention Research Center, 2532 Durant Avenue, Berkeley, CA 94704, USA or to Mark Morgan. St. Patrick’s College. Drumcondra. Dublin 9. Ireland.

This article is a reproduction of that published in: Addictive Behaviors, 1989, 14: pp.159-171. Pagination may not match that of the original. 
particular, respondent errors may lead to mismatches or to a failure to match questionnaires. Such matching errors could result in serious biases in estimating both prevalence statistics and relationships among variables (e.g., Josephson \& Rosen, 1978; Kandel et al., 1978). This paper investigates the use of self-generated codes as a means of linking questionnaires in panel research on adolescent substance use and addresses these issues.

The need for anonymity in studies of adolescent smoking, drinking, and drug use arises for at least two reasons. First, there is evidence that conditions of anonymity enhance the truthfulness of adolescent self-reports of substance use. When anonymity is assured, self-reports can compare very favorably with data obtained using more cumbersome techniques such as the bogus pipeline, randomized response, or biochemical measures (e.g. Akers, Massey, Clarke, \& Lauer, 1983; Hansen, Malotte, \& Fielding, 1985; Murray \& Perry, 1987). Second, concern for the rights and welfare of young respondents often requires that sensitive or potentially damaging information be collected anonymously. School district policies or legal considerations may further necessitate conditions of anonymity when conducting research with adolescents or children.

Several studies have investigated the feasibility of using self-generated codes to maintain anonymity in panel research with adolescents (Carifio \& Biron, 1978; Josephson \& Rosen, 1978; Kandel et al., 1978; Kearney el al., 1984). Estimated matching success in these studies has ranged from $65 \%$ over a two year interval to better than $90 \%$ for $1-3$ day intervals. In the most thorough study (Kearney et al., 1984) it was reported that $92 \%$ of adolescent respondents were correctly matched over a one month period using a seven digit code and $78 \%$ were correctly matched over a one year period.

Although these matching rates are encouraging, they are not the only criteria by which the usefulness of self-generated codes should be judged. The question of sample bias is important also. In two of the three studies that have addressed this question, it was found that matched and unmatched cases differed significantly on a number of important variables (Josephson \& Rosen, 1978; Kandel et al., 1978). Unmatched cases generally were more favorable in their beliefs about smoking, drinking, and other drug use and were more likely to engage in these behaviors than were matched cases. They also did less well in school and were less religious and conventional. These differences may be due to biases introduced by the self-generated code. That is students involved in smoking, drinking, and drug use may be more prone to make errors in the code, and thus be more likely to be unmatched. However, these studies had no means of independently determining which unmatched cases resulted from errors and which resulted from school absences. Thus, some of the apparent bias may, in fact, be due to higher absentee rates among young people involved with drugs and alcohol, rather than to the use of self-generated codes.

In contrast, Kearney et al. (1984) were able to ascertain which students were present at each of their testing sessions for a subgroup of respondents whose questionnaires were identified by a school district code as well as the self-generated code. When students who had been absent at one of the sessions were eliminated, very few significant differences were found between matched and unmatched respondents in terms of alcohol-related knowledge and behaviors, marijuana use, self-esteem, parental support, school achievement, or related variables. Matching status accounted for no more than $5 \%$ of the variance in any of these measures.

In addition to verifying absences. Kearney et al. (1984) also took steps to minimize

This article is a reproduction of that published in: Addictive Behaviors, 1989, 14: pp.159-171. Pagination may not match that of the original. 
data loss resulting from a failure to match questionnaires because of missing data or respondent errors. Specifically, they implemented a two-stage off-one procedure. First, all questionnaires with self-gene rated codes that matched exactly were paired. Then remaining questionnaires which agreed on all but one of the code elements were paired. The success of this procedure was assessed for the subgroup of students whose questionnaires were identified by both school district and self-generated codes. Data were reported showing that the use of the off-one procedure substantially improved the matching rate while resulting in mismatched questionnaires in fewer than $2 \%$ of the cases. Thus, the inclusion of the off-one matches, by increasing the matching rate while adding very few mismatches, probably served to reduce bias.

Although the results of the previous studies suggest that self-generated codes are a potential answer to the problem of maintaining anonymity in longitudinal studies with adolescents, it is desirable to obtain further evidence concerning the usefulness of these codes and the off-one procedure, it is only when a body of evidence based on diverse populations is available that these techniques can be advocated or rejected. In addition, other issues arise regarding self-generated codes that have not been addressed previously. Specifically, only simple differences between matched and unmatched samples have been investigated. None of the available studies have examined the extent to which these techniques may lead to biases in estimates of structural parameters. However, matched and unmatched respondents may differ not only in terms of their beliefs and behaviors, but also in the pattern of relationships among these variables. If this is the case, then the use of self-generated codes in research on adolescent substance use may lead to erroneous conclusions about which factors are more and less important for these behaviors.

The present paper presents a replication and extension of previous research investigating self-generated identification codes. The extent to which such codes, combined with an off-one procedure, were successful in matching questionnaires obtained one month apart was ascertained for a sample of Irish adolescents. Potential sample bias resulting from the use of self-generated identification codes was considered. Going beyond previous studies, the extent to which the use of self-generated codes led to biased estimates of the structural relationships among variables also was ascertained.

\section{Procedure}

\section{METHOD}

Overview. Data were obtained from Irish post-primary students using self-administered questionnaires given on two occasions approximately one month apart. The survey instruments were similar in format for the two sessions. However, the instrument used in the first session emphasized smoking, while that used in the second session emphasized drinking and other drug use.

The surveys were administered to the students as a group in their regular classrooms by trained interviewers. Before each session, the interviewer explained that the study was concerned with smoking, drinking, and other drug use. The students were assured as to the anonymity and confidentiality of their responses. The need for truthful answers was emphasized and the students were specifically instructed not to put their names on the survey materials. A detailed description of the questionnaires and procedures may be found in Grube and Morgan (1986).

Sample. The target population consisted of post-primary students in the greater

This article is a reproduction of that published in: Addictive Behaviors, 1989, 14: pp.159-171. Pagination may not match that of the original. 
Dublin, Ireland area. A sample of 24 schools, stratified for gender composition, size, and type of school (secondary, community/comprehensive, or vocational) was obtained. ${ }^{1}$ Within each school all students from a randomly selected grade level were included in the study.

At the first session 2,927 students completed the questionnaire and at the second session 2,782 did so. They were nearly evenly divided between males (51\%) and females (49\%) and ranged in reported age from just over 9 to 21 years old. However, the vast majority $(99.7 \%)$ fell between 12 and 18 and the median age was about 15 years.

\section{Measures}

Substance use. Measures of substance use included lifetime and current smoking, drinking, and other drug use, and future intentions regarding these behaviors. In the case of smoking, the respondents were asked if they had ever smoked a cigarette and, if so, to indicate on an 8-point scale how many they had smoked each day during the previous month (none - more than 20). Smoking intentions were ascertained by having them indicate on the same scale how many cigarettes they thought they would smoke each day during the next month.

For drinking the respondents were asked if they had ever had a whole drink of cider, beer, wine, or spirits; on how many occasions they had drunk each of these beverages during the previous month (none - more than 10); and the number of occasion's during the next month that they thought they would drink each of them. Overall measures of drinking behaviors and intentions were obtained by summing the items for the individual beverages. As an index of heavy or problem drinking, the students were asked how many times they had ever felt drunk.

Drug use was ascertained by having the students indicate if they had ever used each of ten drugs, how many times they had used each during the past month (none - more than 10), and how often they intended to use each during the next month. Because the responses to these items were very skewed, overall measures were obtained by summing the number of drugs each student used or intended to use, rather than the number of times each drug was used.

Attitudes and beliefs. The students were asked to indicate (a) their attitude or evaluation of smoking, drinking, and drug use on a series of bi-polar scales (e.g., pleasant-unpleasant; likedislike); (b) how often they believed their mothers, fathers, best friends, and other good friends smoked cigarettes, drank alcohol, and used other drugs ${ }^{2}$, and (c) the extent to which they believed these others disapproved of these behaviors for the student. Indices of overall attitude, parental behavior, peer behavior, parental disapproval, and peer disapproval were formed by averaging the relevant items within each domain of substance use.

\footnotetext{
${ }^{1}$ Irish post-primary schools are equivalent to grades 8-12 in American school systems. They grant two types of degrees by examination: an intermediate certificate after three years of schooling and a leaving certificate after five years. Secondary schools focus on an academic curriculum and are slate subsidized private institutions run by religious orders or an independent board of governors. Vocational schools arc similar to secondary schools, but more emphasis is placed on non-academic subjects. Comprehensive and community schools are run by local boards and combine academic and technical education depending upon the needs and interests of the individual student.

2 The students were not asked to report on parental drug use because it was expected that this behavior would be too infrequent lo be meaningful.
} match that of the original. 
Other variables. Social bonding to school, religion, and parents, and involvement in other problem behaviors also were ascertained. Specifically, respondents were asked (a) how well they did in school relative to other students; (b) how important doing well in school was to them personally; (c) how well they got along with each of their parents; (d) how important religion was to them; (e) how often they prayed; and (f) how often they engaged in each of five problem behaviors (swearing, lying to parents, lying to teachers, stealing, vandalism). Background characteristics including age, gender, father's occupation, and weekly spending money also were ascertained.

\section{Matching procedure}

The self-generated identification code consisted of seven elements: gender, month, day, and year of birth; number of older brothers; number of older sisters; and first initial of mother's first name. The school and class level from which the questionnaire originated also were coded on the questionnaires and were used in the matching procedure. The matching took place in two stages. In the first stage, only those questionnaires with perfect matches on the school and class level code and all seven elements were paired. In the second stage, an off-one procedure was implemented. Thai is, remaining questionnaires were paired if they matched on the school and class level code and differed on only one of the remaining code elements.

\section{RESULTS}

\section{Matching success}

After eliminating eight cases with duplicate codes and 36 cases with missing data on two or more code elements, a total of 1677 pairs of questionnaires with perfect matches on all seven elements was obtained. Conservatively, this figure represents about $60 \%$ of the possible matches (number of matches/number of students attending the smaller session). If a usual absentee rate of $15 \%$ is assumed, based on estimates provided by school authorities, this rate increases to $71 \%$ of the maximum number of possible matches. These figures are in close agreement with those obtained in previous research using self-generated identification codes. An additional set of 399 off-one matches was obtained after eliminating 10 duplicate matches. Thus the off-one procedure improved the matching rate by about $24 \%$. When the exact and off-one matches were combined, a total of 2,076 questionnaires were paired representing $75 \%$ of the maximum number possible. Taking absences into account increased this percentage to $88 \%$.

Because the questionnaires were completely anonymous, it was not possible to directly ascertain if the off-one procedure resulted in mismatching. However, some indication of this potential problem can be obtained by examining the test-retest reliabilities for the exact and offone matching groups. If the off-one procedure were associated with a significant level of mismatching, then it would be expected that the test-retest reliabilities for this group would be tower than for the exactly matched group.

Table 1 shows the reliabilities for the key substance use scales that were repeated at the two sessions: (a) number of cigarettes smoked each day during the previous month; (b) frequency of drinking during the previous month; (c) expected frequency of drinking during the next month; (d) number of drugs used during the previous month; and (e) the expected number of drugs to be used during the next month. It can be seen that the reliabilities for the exact and off-one groups are very similar. 
Table I. Test-retest reliabilities for current substance use and intention measures

\begin{tabular}{lrrr}
\hline & \multicolumn{3}{c}{ Group } \\
\cline { 2 - 4 } Measure & Exact & Off-One & $\begin{array}{c}\text { Total Matched } \\
\text { Sample }\end{array}$ \\
\hline Smoking & .81 & .78 & .80 \\
& $(1671)$ & $(399)$ & $(2070)$ \\
Drinking & .73 & .69 & .73 \\
Drinking intention* & $(1650)$ & $(390)$ & $(2040)$ \\
& .76 & .68 & .75 \\
Drug use & $(1650)$ & $(387)$ & $(2037)$ \\
& .45 & .44 & .43 \\
Drug use intention* & $(1635)$ & $(393)$ & $(2048)$ \\
& .56 & .65 & .58 \\
& $(1653)$ & $(394)$ & $(2047)$
\end{tabular}

Note. Reliability coefficient is Spearman's Rho. Numbers in parentheses are group $n \mathrm{~s}$.

*Reliability coefficients for the exact and off-one groups differ significantly $(p<.05)$ using a $z$-test.

Two coefficients differed significantly $(p<.05)$ between the exact and off-one groups, but the differences were in opposite directions. In the case of drinking intentions, the reliability for the exact group was higher than for the off-one group. Conversely, in the case of drug use intentions, the reliability for the off-one group was higher. Thus, the off-one procedure does not appear to have led to appreciable mismatching.

\section{Sample bias}

Sample bias can be addressed in two ways. First, those who are included in the sample on the basis of the self-generated codes can be compared with those excluded. This comparison addresses the question as to whether exactly matched, off-one, and unmatched respondents differ in important ways. Second, it is possible to compare the combined matched cases with the total sample (matched + unmatched cases). This latter comparison is a more appropriate test of sample bias because it indicates the extent to which using only matched cases would affect population estimates. Both comparisons will be made here.

Background characteristics. In terms of background characteristics, somewhat fewer males were exactly matched (43\%) compared with females (51\%) and more males $(46 \%)$ than females $(37 \%)$ were unmatched, $\mathrm{x}^{2}(2)=33.92, p<.001$. The matching groups also differed significantly on the occupational statuses of their fathers, $\mathrm{x}^{2}(14)=23.62, p<.05$, with the unmatched cases reporting somewhat lower occupational status than the exact and off-one groups. (Occupational status was coded using an adaptation of the Hall-Jones scale developed for the Irish context. See MacGreil, 1977.) Finally, the unmatched group had slightly more spending money available to them each week than did the two matched groups, $\mathrm{F}(2.2788)=8.72, p<.001$. The exact, offone, and unmatched groups received an average of 3.34, 3-70, and 4.02 Irish pounds each week, respectively. However, the differences in these background characteristics were quite small and accounted for only about 
Table 2. Percentage of matching groups reporting lifetime and current drinking, smoking. and drug use at phase I

\begin{tabular}{lccccc}
\hline \multirow{2}{*}{$\begin{array}{l}\text { Substance Use } \\
\text { Behavior }\end{array}$} & $\begin{array}{c}\text { Exact } \\
(\mathrm{n}=1657)\end{array}$ & $\begin{array}{c}\text { Off-One } \\
(\mathrm{n}=396)\end{array}$ & $\begin{array}{c}\text { Unmatched } \\
(\mathrm{n}=828)\end{array}$ & $X^{2}$ & $\eta^{2}$ \\
\hline \multicolumn{5}{c}{ Lifetime } \\
Smoking & 63.1 & 71.5 & 72.1 & $24.48^{* *}$ & .01 \\
Drinking & 61.2 & 68.7 & 70.7 & $24.52^{* *}$ & .01 \\
Drug use & 17.8 & 23.0 & 29.3 & $43.47^{* *}$ & .01 \\
\hline \multicolumn{5}{c}{ Current } \\
Smoking & 35.2 & 43.4 & 43.1 & $19.19^{* *}$ & .01 \\
Drinking & 49.4 & 58.8 & 52.8 & $12.08^{* *}$ & $<.01$ \\
Drug use & 12.3 & 17.9 & 17.0 & $14.47^{* *}$ & $<.01$ \\
\hline
\end{tabular}

${ }^{*} p<.01, * * \mathrm{p}=.001$.

$1 \%$ of the variance at most. Moreover, the groups did not differ significantly in age $(F<1)$. Importantly, in all cases the population estimate obtained from the combined matched groups was very similar to that obtained from the total sample. Thus, the combined matched groups contained only about $4 \%$ fewer males than the total sample, father's occupational status differed by only $.6 \%$ in any category, on the average, and mean weekly spending money differed by only 18 pence.

Lifetime substance use. Table 2 shows the percentage of each matching group that reported ever having smoked cigarettes, drunk alcohol, or used drugs. The associated chi-square statistics and if, a measure of variance accounted for, are shown also. It can be seen that a somewhat higher percentage of the unmatched cases reported that they had ever tried cigarettes, alcohol, or other drugs. However, although all of the overall differences in lifetime substance use were significant, group membership accounted for only $1 \%$ of the variance in these behaviors. Moreover, the prevalence rates for the combined matched sample were very similar to those for the total sample, averaging only about $2 \%$ lower. Thus, the lifetime smoking rate for the total sample was $67 \%$ compared with $65 \%$ for the combined groups. Similarly the lifetime drinking rate for the total sample was $65 \%$ as opposed to $63 \%$ for the combined matched groups. The comparable figures for drug use are $22 \%$ and $19 \%$.

Current substance use. Table 2 also displays the percentage of each matching group that reported smoking, drinking, and drug use during the previous month. The three groups differed significantly on every one of these behaviors. The off-one and unmatched group closely resembled one another and reported the highest frequency of current smoking, drinking, and drug use. These behaviors were less prevalent among the exactly matched students. Overall, however, the differences tended to be very small and accounted for less than $1 \%$ of the variance in substance use, on the average. Moreover, the prevalence rates for the combined matching groups are similar to those for the total sample. Thus. $38.6 \%$ of the total sample reported smoking during the past month compared with $36.8 \%$ of the matched sample. The respective prevalence rates were $51.6 \%$ and $51.2 \%$ for drinking, and $14.4 \%$ and $13.4 \%$ for drug use. 
Although the data are not shown here, analyses of variance were also conducted on the smoking, drinking, and drug use scales. Overall, the groups differed significantly on each of these scales. In contrast to the simple prevalence data, the off-one group was more similar to the exactly matched group than to the unmatched group on these measures. Comparisons of the individual means with $t$-tests using the Bonferroni procedure to protect the alpha levels showed that the two matched groups did not differ significantly from one another, while the unmatched respondents reported smoking more cigarettes, drinking more often, and using more drugs than either of the matched groups. However, group membership accounted for only $1-2 \%$ of the variance in these measures.

The same pattern was evident when heavy or problem drinking was considered. Overall, the three matching groups differed significantly in their frequency of drunkenness, $F(2,2914)=$ $15.16, p<.001$. On the average, the exact, off-one, and unmatched respondents reported having been drunk 1.95, 2.48, and 2.84 times, respectively. Comparisons of the individual means with / tests and the Bonferroni procedure, indicated that the exactly matched group reported having been drunk less often than either the off-one or unmatched group. These latter groups did not differ significantly from one another. Overall, however, the difference was slight with matching group accounting for only $1 \%$ of the variance in this behavior. The frequency of drunkenness was 2.28 times for the total sample compared with 2.05 times for the matched respondents.

Attitudes and normative beliefs. The matching groups also differed significantly in [heir attitudes and normative beliefs regarding smoking, drinking, and other drug use (Table 3). As might be expected from the preceding analyses, respondents in the exactly matched group were less favorable in their attitudes towards these behaviors and less likely to report that their friends and parents smoked, drank, or used other drugs. They also reported that these others were less approving of these behaviors. The unmatched group tended to be most favorable in these beliefs and the off-one group tended to be intermediate. However, only for one measure, perceived drug use by peers, did the magnitude of the effect approach substantive significance $\left(n^{2}=.05\right)$.

Problem behaviors. Comparisons of the three matching groups on other problem behaviors are given in Table 4. In general, the exactly matched group showed a tendency to engage in problem behaviors less frequently than the other groups. Thus, they were less likely to admit that they swore, lied to teachers or parents, purposely damaged property, or stole. The exactly matched group showed the lowest frequency of these behaviors and the off-one group was intermediate. However, differences in matching account for only about $1 \%$ of the variance in the problem behaviors, on the average.

Social bonding. The matching groups also were compared on social bonding to school, parents, and religion (Table 5). The unmatched group, compared with the exactly matched group, reported that (a) it was less important to them to do well in school; (b) religion was less important to them; and (c) they prayed less frequently. The off-one group was again intermediate. As with the previous analyses, the differences were very small, accounting for less than $1 \%$ of the variance, on average. In addition, the groups did not differ significantly on self-reported achievement in school or on their reported relationships with their parents. 
Table 3. Comparison of matching groups on substance use attitudes and normative beliefs

\begin{tabular}{|c|c|c|c|c|c|}
\hline \multirow[b]{2}{*}{ Belief } & \multicolumn{3}{|c|}{ Group } & \multirow[b]{2}{*}{$F$} & \multirow[b]{2}{*}{$n^{2}$} \\
\hline & Exact & Off-One & Unmatched & & \\
\hline \multicolumn{6}{|c|}{ Smoking } \\
\hline Attitude & $2.21^{\mathrm{a}, \mathrm{b}}$ & $2.46^{\mathrm{a}}$ & $2.37^{\mathrm{b}}$ & $10.72 * * *$ & $<.01$ \\
\hline Parental smoking & $2.45^{\mathrm{a}}$ & 2.59 & $2.64^{\mathrm{a}}$ & $4.02 *$ & $<.01$ \\
\hline Peer smoking & $2.08^{\mathrm{a}, \mathrm{b}}$ & $2,39^{\mathrm{a}}$ & $2.47^{\mathrm{b}}$ & $30.64 * * *$ & .02 \\
\hline Parental approval & $1.89^{\mathrm{a}, \mathrm{b}}$ & $2.09^{\mathrm{a}}$ & $2.04^{\mathrm{b}}$ & $7.47 * * *$ & $<.01$ \\
\hline Peer approval & $4.04^{\mathrm{a}, \mathrm{b}}$ & $4.20^{\mathrm{a}}$ & $4.18^{\mathrm{b}}$ & $5.27 * *$ & $<.01$ \\
\hline \multicolumn{6}{|l|}{ Drinking } \\
\hline Altitude & $2.98^{\mathrm{a}, \mathrm{b}}$ & $3.20^{\mathrm{a}}$ & 3.28 & $14.79 * * *$ & .01 \\
\hline Parental drinking & 2.51 & 2.33 & 2.54 & .40 & - \\
\hline Peer drinking & $1.76^{\mathrm{a}}$ & $1.87^{\mathrm{a}, \mathrm{b}}$ & $2.10^{\mathrm{a}, \mathrm{b}}$ & $32.43 * * *$ & .02 \\
\hline Parental approval & $1.94^{\mathrm{a}}$ & 2.03 & $2.19^{\mathrm{a}}$ & $9.29 * * *$ & $<.01$ \\
\hline Peer approval & $3.96^{\mathrm{a}}$ & 4.11 & $4.22^{\mathrm{a}}$ & $10.01 * * *$ & $<.01$ \\
\hline \multicolumn{6}{|l|}{ Drug Use } \\
\hline Attitude & $1.79^{\mathrm{a}}$ & $1.91^{\mathrm{b}}$ & $2.24^{\mathrm{a}, \mathrm{b}}$ & $30.42 * * *$ & .02 \\
\hline Peer drug use & $1.19^{\mathrm{a}}$ & $1.27^{\mathrm{b}}$ & $1.64^{a, b}$ & $67.06 * * *$ & .05 \\
\hline Parental approval & $1.06^{\mathrm{a}}$ & $1.09^{\mathrm{b}}$ & $1.20^{\mathrm{a}, \mathrm{b}}$ & $21.19 * * *$ & .02 \\
\hline Peer approval & $2.26^{\mathrm{a}}$ & $2.36^{\mathrm{b}}$ & $2.70^{\mathrm{a}, \mathrm{b}}$ & $24.87 * * *$ & .02 \\
\hline
\end{tabular}

Note. Smoking beliefs were obtained at Phase I and drinking and drug use beliefs at Phase II. For the exact match group the $n$ s were 1623, 1660, and 1666 for smoking, drinking, and drug use, respectively. The corresponding $n$ s were 387, 389, and 395 for the off-one group and 811,667, and 687 for the unmatched group. Means within each row with common superscripts differ significantly using $t$-test protected wild the Bonferroni procedure. All measures were on live-point scales and higher scores indicate beliefs more supportive; of substance use.

${ }^{*} p<.05 .{ }^{* *} p<.01 .{ }^{* * *} \mathrm{p}<.001$.

Table 4. Comparison of matching groups on frequency of other problem behaviors

\begin{tabular}{lccccr}
\cline { 2 - 4 } & \multicolumn{3}{c}{ Group } & & \\
\cline { 2 - 4 } Problem Behavior & $\begin{array}{c}\text { Exact } \\
(\mathrm{n}=1661)\end{array}$ & $\begin{array}{c}\text { Off-One } \\
(\mathrm{n}=396)\end{array}$ & $\begin{array}{c}\text { Unmatched } \\
(\mathrm{n}=688)\end{array}$ & \multicolumn{1}{c}{$F$} & \multicolumn{1}{c}{$\eta^{2}$} \\
\hline Swearing & $4.03^{\mathrm{a}}$ & $4.17^{\mathrm{a}}$ & 4.14 & $4.55^{*}$ & $<.01$ \\
Lying to teachers & $2.81^{\mathrm{a}}$ & $2.90^{\mathrm{a}}$ & $3.09^{\mathrm{a}, \mathrm{b}}$ & $13.90^{* * *}$ & .01 \\
Lying to parents & $2.72^{\mathrm{a}}$ & 2.80 & $2.88^{\mathrm{a}}$ & $5.44^{* *}$ & $<.01$ \\
Stealing & $1.86^{\mathrm{a}}$ & $1.94^{\mathrm{b}}$ & $2.15^{\mathrm{a}, \mathrm{b}}$ & $16.61^{* *}$ & .01 \\
Vandalism & $1.54^{\mathrm{a}}$ & $1.61^{\mathrm{b}}$ & $1.92^{\mathrm{a}, \mathrm{b}}$ & $34.23^{* * *}$ & .02 \\
\hline
\end{tabular}

Note. Means within each row with common superscripts differ significantly using $t$-tests protected with the Bonferroni procedure. Scales range from 1 (never) to 1 (verve often).

${ }^{*} p<.05 .{ }^{* *} \mathrm{p}<.01,{ }^{* * *} \mathrm{p}<.001$.

This article is a reproduction of that published in: Addictive Behaviors, 1989, 14: pp.159-171. Pagination may not match that of the original. 
Table 5. Comparison of matching groups on social bonding beliefs and behaviors

\begin{tabular}{|c|c|c|c|c|c|}
\hline \multirow[b]{2}{*}{ Variable } & \multicolumn{3}{|c|}{ Group } & \multirow[b]{2}{*}{$F$} & \multirow[b]{2}{*}{$n^{2}$} \\
\hline & $\begin{array}{c}\text { Exact } \\
(\mathrm{n}=1623)\end{array}$ & $\begin{array}{l}\text { Off-One } \\
(\mathrm{n}=369)\end{array}$ & $\begin{array}{l}\text { Un matched } \\
(\mathrm{n}=753)\end{array}$ & & \\
\hline Social achievement & 3.89 & 3.83 & 3.78 & 2.08 & - \\
\hline Importance of school & $4.51^{\mathrm{a}}$ & 4.42 & $4.36^{\mathrm{a}}$ & $10.05 * *$ & .01 \\
\hline Relationship with mother & 4.59 & 4.53 & 4.51 & 2.96 & - \\
\hline Relationship with father & 4.38 & 4.45 & 4.31 & 2.85 & - \\
\hline Importance of religion & 3.37 & 3.55 & 3.43 & $4.28 *$ & $<.01$ \\
\hline Frequency of prayer & $3.61^{\mathrm{a}}$ & 3.41 & $3.27^{\mathrm{a}}$ & $11.03 * *$ & .01 \\
\hline
\end{tabular}

Note. Means within each row with common superscripts differ significantly using $t$-tests protected with the Bonferroni procedure. All items were presented as rive-point scale; with a higher score representing closer social bonding.

$* \mathrm{p}<, 05 . * * \mathrm{p}<.001$.

Structural relationships. Potential biases in estimating the structual relationships among variables were investigated by examining the standardized regression coefficients obtained for the matched and unmatched groups when predicting smoking, drinking, and other drug use from normative beliefs and attitudes. These coefficients are shown in Table 6.

The important comparisons in this table are between the combined matched groups (column 3), the unmatched group (column 4) and the total sample (column 5). For the most part, the regression coefficients obtained for these groups of respondents appear to be very similar. The equivalence of these coefficients was formally tested using a hierarchical procedure in which matching group and then the interactions between matching group and the belief measures were added to the equations. The increase in explained variance $\left(\Delta R^{2}\right)$ resulting from the addition of the interactions was then examined for statistical and substantive significance. Matching group was coded as a dummy variable (matched versus unmatched) and the belief measures were transformed into mean deviation form for these analyses. (A more complicated coding scheme that contrasted the exact, off-one, and unmatched respondents yielded results very similar to those reported here.) The interactions were represented by the relevant product terms.

For smoking and drinking, the increase in $\mathrm{ft}^{2}$ resulting from the addition of the interaction terms was statistically significant $(p<.01)$, but substantively meaningless $\left(\Delta \mathrm{R}^{2}<.01\right.$ in each case). However, the increase in explained variance for drug use was statistically significant, $F$ (4, $2735)$ - 48.27, $\mathrm{p}<.001$, and approached substantive significance $\left(\Delta R^{2}=.05\right)$. An examination of Table 6 and the significance tests for the individual interaction terms suggests that the largest differences occur for attitude, peer approval of drug use, and perceived peer drug use. The regression coefficients associated with these variables are all somewhat larger for the unmatched sample compared with the combined matched groups. Even so, the absolute differences between the coefficients for the combined matched groups and the total sample are relatively small, the largest being about .05. In addition, comparing the coefficients for [he matched and total samples indicates that similar conclusions would be reached in both cases concerning the size, direction, and the relative importance of effects. 
Table 6. Comparison of Standardized regression coefficients predicting smoking, drinking, and other drug use

\begin{tabular}{|c|c|c|c|c|c|}
\hline \multirow[b]{2}{*}{ Predictor } & \multicolumn{5}{|c|}{ Group } \\
\hline & $\begin{array}{c}\text { Exact } \\
\text { Matches }\end{array}$ & $\begin{array}{l}\text { Off-One } \\
\text { Matches }\end{array}$ & $\begin{array}{c}\text { All } \\
\text { Marches }\end{array}$ & Unmatched & $\begin{array}{l}\text { Matched + } \\
\text { Unmatched }\end{array}$ \\
\hline \multicolumn{6}{|c|}{ Smoking Phase I } \\
\hline Peer approval & $-.11 *$ & -.08 & $-.11 *$ & $-.11 *$ & $-.11 *$ \\
\hline Parental approval & $.14^{*}$ & $.14^{*}$ & $.14^{*}$ & $.17^{*}$ & $.15^{*}$ \\
\hline Peer smoking & $.43 *$ & $.31 *$ & $.40^{*}$ & $.39 *$ & $.40 *$ \\
\hline Parental smoking & $.04 *$ & .06 & $.04 *$ & $.07 *$ & $.05^{*}$ \\
\hline Altitude & $.33 *$ & $.44^{*}$ & $.35^{*}$ & $.29 *$ & $.32 *$ \\
\hline$R^{2}$ & $.42 *$ & $.44^{*}$ & $.42 *$ & $.39 *$ & $.41 *$ \\
\hline$n$ & $(1623)$ & (387) & $(2010)$ & $(810)$ & $(2820)$ \\
\hline \multicolumn{6}{|c|}{ Drinking Phase II } \\
\hline Peer approval & $-.10 *$ & -.10 & $-.10 *$ & $-.08 *$ & $-.10 *$ \\
\hline Parental approval & $.13^{*}$ & .08 & $.12 *$ & $.10^{*}$ & $.11^{*}$ \\
\hline Peer drinking & $.42 *$ & $-47 *$ & $.43^{*}$ & $.30^{*}$ & $.39 *$ \\
\hline Parental drinking & .02 & .07 & .03 & .04 & $.03 *$ \\
\hline Altitude & $.29 *$ & $.26^{*}$ & $.29 *$ & $.31 *$ & $.28 *$ \\
\hline$R^{2}$ & $.41^{*}$ & $.39 *$ & $.41^{*}$ & $.29^{*}$ & $.35^{*}$ \\
\hline$n$ & $(1660)$ & $(389)$ & $(2049)$ & $(663)$ & $(2712)$ \\
\hline \multicolumn{6}{|c|}{ Drug Use Phase II } \\
\hline Peer approval & $-.05^{*}$ & -.03 & $-.06^{*}$ & $-.15^{*}$ & $-.11 *$ \\
\hline Parental approval & $.20^{*}$ & .00 & $.16^{*}$ & $.13^{*}$ & $.14^{*}$ \\
\hline Peer drug use & $.48-$ & $.39 *$ & $.46^{*}$ & $.51 *$ & $.51 *$ \\
\hline Attitude & $.10^{*}$ & $.32 *$ & $.12 *$ & $.17^{*}$ & $.11 *$ \\
\hline$R^{2}$ & $.33 *$ & $.35^{*}$ & $.31^{*}$ & $.36^{*}$ & $.33 *$ \\
\hline$n$ & $(1666)$ & $(395)$ & (2061) & $(684)$ & $(2745)$ \\
\hline
\end{tabular}

It has been suggested that self-generated codes coupled with an off-one matching procedure are an effective means of linking questionnaires in panel studies of adolescent substance use without compromising confidentiality or anonymity (Kearney et al., 1984). In the present study it was found that a seven element code was successful in exactly pairing $71 \%$ of the maximum possible matches over a one-month period when school absences were taken into account. Allowing the codes to differ on one element in order to compensate for respondent errors significantly improved the matching rate to about $08 \%$. A comparison of the test-retest reliabilities for exactly matched and off-one groups on measures of substance use indicated that they generally were comparable. Thus, the off-one procedure probably did not lead to appreciable mismatching of questionnaires.

In terms of sample bias, comparisons of the exactly matched, off-one, and unmatched groups indicated that the unmatched students were more involved in substance use and had more favorable attitudes and normative beliefs toward these behaviors. They also admitted that they engaged in other problem behaviors more frequently and were less closely bonded to parents, school, and religion than were the unmatched ones. In addition, unmatched cases were more likely to be male, to 
have fathers with lower occupational status, and to have more spending money. The off-one matches usually were intermediate on these variables. However, these differences among the groups generally were very small, accounting for only $2 \%$ or $3 \%$ of the variance, on the average. The addition of the off-one matches generally improved the quality of the data by moving the estimates of substance use and of older behaviors and beliefs closer to those obtained for the total sample. For example, lifetime drinking rates among the exactly matched respondents were about $4 \%$ below those for the total sample. When the off-one matches were combined with the exact matches, this discrepancy was halved. In the case of current substance use, the differences in prevalence rates between the matched and total sample were even smaller.

There are at least two possible explanations for the small differences in belief and behavior between matched and unmatched respondents. First, they may reflect the fact that students who make irreconcilable mistakes in their self-generated codes are more involved in smoking, drinking, drug use, and other problem behaviors. To the extent that this is true, then these differences represent very small sample biases introduced by the use of this procedure. Another possibility is that the differences are a result of higher absentee rates among smokers, drinkers and drug users, rather than the use of self-generated codes. That is, the data for the combined matched groups may accurately reflect the slate of affairs for students who actually attended both sessions, but do so to a lesser extent for the general student population. In this latter case, the small biases result not from using self-generated codes, but rather from using school based surveys without follow-up attempts for absentees.

The fact that students who made one error in completing the code (off-one matches) fell between the exact and unmatched respondents on most variables suggests that absenteeism alone cannot account for the differences and that both interpretations may be partially true. However, regardless of the interpretation, the differences between matched and unmatched respondents generally are loo small to be of substantive significance.

The effects of using self-generated identification codes on estimates of structural parameters were investigated in a series of regression analyses predicting smoking, drinking, and other drug use. For smoking and drinking it was found that the results generally were quite similar for the combined exact and off-one groups, the unmatched group, and the total sample. In no case did the estimates differ substantially. For drug use some differences were found among the structural parameters for the matching groups. Importantly, however, these differences tended to be small and the interpretations of the coefficients in terms of size, direction, and relative importance were largely unaffected.

In sum, the present study provides evidence in support of the use of self-generated codes to match questionnaires in panel and longitudinal studies with adolescents. These codes may be particularly useful in studies of adolescent substance use or when the subject matter of the survey is otherwise sensitive. In such cases self-generated codes represent a viable means of linking questionnaires over time without compromising respondent anonymity, thereby protecting the rights of research participants and improving data quality. Using an off-one matching procedure to compensate for respondent errors significantly improves the matching rate and may reduce biases that would result if only exactly matched respondents were used.

This article is a reproduction of that published in: Addictive Behaviors, 1989, 14: pp.159-171. Pagination may not match that of the original. 


\section{REFERENCES}

Akers, R.L., Massey, J., Clarke. W., \& Lauer, R. M. (1983). Are self-reports of adolescent deviance valid? Biochemical measures, randomized response, and the bogus pipeline in smoking behavior. Social Forces 62, 234-251.

Carifio, J., \& Biron, R. (1978). Collecting sensitive data anonymously: The CDRGP technique. Journal of Alcohol and Drug Education 23. 47-66.

Grube, J. W., \& Morgan. M. (1986). Smoking, drinking, and other drug use among Dublin postprimary school pupils (paper No. 132. Dublin: The Economic and Social Research Institute.

Hansen, W.B., Malotte. C.K., \& Fielding. J.E. (1985). The bogus pipeline revisited: The use of the threat of detection as a means of increasing self-reports of tobacco use. Journal of Applied Psychology, 70, 789-792.

Josephson, E., \& Rosen. M.A. (1978). Panel loss in a high school drug study. In D.B. Kandel (Ed.), Longitudinal research in drug use: Empirical findings and methodological issues (pp. 115-133), New York: Hemisphere.

Kandel, D.B., Kessler, R.C., \& Margulies, R.Z. (1978). Antecedents of adolescent initiation into stages of drug use: A developmental analysis. In D.B. Kandel (Ed.). Longitudinal research in drug use: Empirical findings and methodological issues (pp. 73-99). New York: Hemisphere.

Kearney, K.A., Hopkins, R.H., Mauss, A.L., \& Weisheit, R.A. (1984). Self-generated identification codes for anonymous collection of longitudinal questionnaire data. Public Opinion Quarterly, 48, 370-378.

MacGréil, M. (1977). Prejudice and tolerance in Ireland. Dublin: College of Industrial Relations.

Murray, D.M., \& Perry, C.L. The measurement of substance use among adolescents: When is the 'bogus pipeline' method needed? Addictive Behaviors, 12, 225-233.

This article is a reproduction of that published in: Addictive Behaviors, 1989, 14: pp.159-171. Pagination may not match that of the original. 